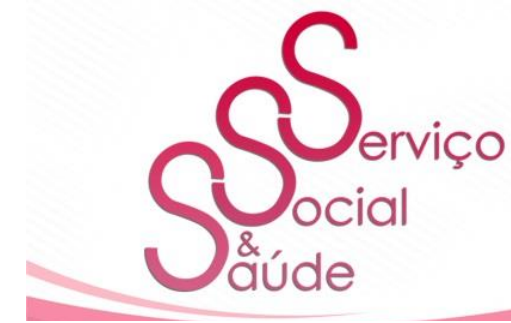

ISSN 2446-5992

(๑) $\odot \odot$

doi: $10.20396 /$ sss.v18i0.8656828

\title{
SERVIÇO SOCIAL E CUIDADOS PALIATIVOS
}

\author{
Social Work and Palliative Cares
}

\author{
Patrícia Barreto Cavalcanti ${ }^{1}$ \\ Clara Isabel Nóbrega Saturnino ${ }^{2}$ \\ Ana Paula Rocha Sales de Miranda ${ }^{3}$
}

\section{RESUMO}

Este artigo objetiva verificar o conhecimento de assistentes sociais e Residentes em Serviço Social do Hospital Universitário Lauro Wanderley (HULW) sobre os cuidados paliativos e identificar quais as principais ações relativas à categoria nesta estratégia terapêutica. Quanto aos procedimentos metodológicos, trata-se de uma pesquisa de campo, exploratória, descritiva e de cunho qualiquantitativo, realizada mediante aplicação de questionário semiestruturado entre os meses de agosto e dezembro de 2016, cuja amostra foi definida por critérios de acessibilidade, composta por 20 profissionais e 5 Residentes de Serviço Social do HULW. Como principais resultados, verificou-se que há alto desconhecimento sobre o que são cuidados paliativos e quais as ações cabíveis ao Serviço Social, baixa articulação em equipe multiprofissional para esta intervenção, incipiente discussão da temática no processo formativo, aproximação com a temática tão somente nos serviços, inexistência de condições objetivas favoráveis a esta estratégia na instituição e junto às equipes de trabalho, e, embora tenha sido relatada congruência ideal entre o Projeto Ético-Político Profissional do Serviço Social e os cuidados paliativos, destacou-se a necessidade de sua compreensão apropriada pela categoria e domínio das dimensões que compõem a profissão para que se possa empreender um cuidado ético e um trabalho consciente e propositivo que concorram para materialização do Projeto Profissional e adequada oferta dos cuidados paliativos e assistência a usuários e seus familiares.

PALAVRAS-CHAVE: Cuidados paliativos. Serviço Social. Saúde.

\section{ABSTRACT}

This objective article to verify the knowledge of social and Resident assistants in Social Service of the University Hospital Lauro Wanderley (HULW) on the palliative cares and to identify to which the main

\footnotetext{
${ }^{1}$ Professora Titular do Departamento de Serviço Social da UFPB. Doutora em Serviço Social pela PUC-SP. Coordenadora do Setor de Estudos e Pesquisas em Saúde e Serviço Social- SEPSASS. E-mail: patriciabcaval@gmail.com. Telefone 5583988353601.

2 Especialista Multiprofissional em Atenção ao Paciente Crítico pelo Hospital Universitário Lauro Wanderley. Pesquisadora do Setor de Estudos e Pesquisas em Serviço Social, SEPSASS. Telefone 5583 32266001, e-mail: clarasaturnino15@gmail.com.

${ }^{3}$ Professora do Departamento de Serviço Social da Universidade Federal da Paraíba-UFPB. Doutora em Serviço Social pelo Programa de Estudos Pós-Graduados em Serviço Social pela Pontifícia Universidade Católica de São Paulo. E-mail: aprmiranda2@gmail.com. Telefone: 558399012112.
} 


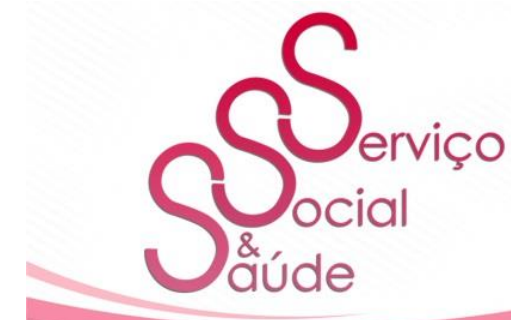

ISSN 2446-5992

(c) 10 (3)

doi: $10.20396 /$ sss.v18i0.8656828

relative actions to the category in this therapeutical strategy. How much to the methodological procedures, one is about a research of field, exploratory, descriptive and of quantitative and qualitative matrix, carried through by means of application of semistructuralized questionnaire enters the months of August and December of 2016, whose sample was defined by criteria of accessibility, composed for 20 professionals and 5 Residents of Social Service of the HULW. As main results, it was verified that it has high unfamiliarity on what they are well-taken care of palliative and which the cabbies actions to the Social Service, low joint in multiprofessional team for this intervention, incipient quarrel of the thematic one in the formative process, approach with the thematic one so only in the services, inexistence of objective conditions favorable to this strategy in the institution and next to the teams of work, and, even so has been told ideal congruence enters the Project Professional Ethical-Politician of the Social Service and the palliative cares, it was distinguished necessity of its appropriate understanding for the category and domain of the dimensions that they compose the profession so that if it can undertake an ethical care and conscientious and propositive a work that concurs for materialization of the Professional and adjusted Project offers of the palliative cares and assistance the users and its familiar ones.

KEYWORDS: Palliative cares. Social Work. Health.

\section{INTRODUÇÃO}

Este artigo objetiva verificar o conhecimento de assistentes sociais e Residentes que atuam na Unidade de Terapia Intensiva (UTI) e nos demais setores do Hospital Universitário Lauro Wanderley (HULW) acerca dos cuidados paliativos (CPs) e identificar quais as principais ações relativas ao Serviço Social nessa estratégia terapêutica.

Cuidados paliativos são medidas não curativas, desenvolvidas junto a usuários que apresentam progressão da doença, sem perspectiva de melhora. Tais intervenções na saúde global são realizadas por profissionais das Ciências da Saúde, Sociais e Humanas, tanto em unidades hospitalares, UTIs e ambulatórios, como em atendimentos domiciliares (FONSECA., A; FONSECA, M., 2010). Representam estratégias terapêuticas a serem aplicadas em todos os âmbitos da saúde, voltadas à melhoria do atendimento de usuários e de suas famílias no confronto de doenças que ameaçam a vida, proporcionando maior conforto e alívio de uma maneira mais humanizada e efetiva (CARDOSO et al., 2013).

Assim, o paliar é uma estratégia a ser empregada pelos profissionais de saúde, sempre que seja identificada sua necessidade na assistência ao usuário, mediante abordagem multiprofissional, voltada a uma assistência de qualidade e sistêmica para pacientes que se 


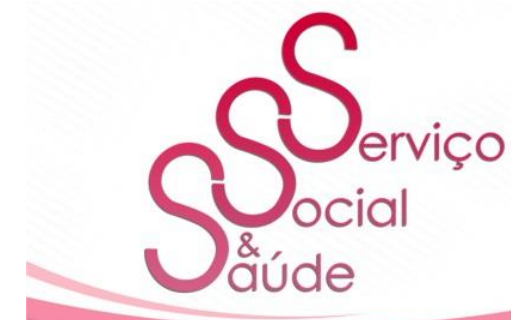

ISSN 2446-5992

(c) (1) (3)

doi: $10.20396 /$ sss.v18i0.8656828

encontram sem possibilidade de cura e para seus familiares durante todo o processo da doença, o que ratifica a retomada de questões éticas e humanas que muitas vezes são negligenciadas e/ou secundarizadas face aos problemas macroestruturais, no âmbito da assistência em saúde, e dá destaque à autonomia individual como um dos valores centrais dos cuidados paliativos (OLIVEIRA; SILVA, 2010). Cabe ressaltar que, embora a ênfase dos CPs recaia em geral sobre pessoas em estado terminal, eles envolvem todas as fases de doenças em estágio progressivo e sem cura, a partir da sua detecção.

De acordo com a Australian National Sub-acute and Non-acute Patient (ANSNAP) Classification, descrevem-se quatro fases paliativas, em função do estágio da doença, correspondendo cada uma a diferentes níveis de complexidade:

- Aguda - refere-se a uma fase de desenvolvimento inesperado de um problema ou em que há um aumento significativo na gravidade dos problemas já existentes;

- Em deterioração - fase em que ocorre um desenvolvimento gradual de problemas, sem que haja necessidade de uma alteração súbita no manejo da situação; são doentes que não estão ainda na fase seguinte;

- Terminal - diz respeito à fase em que a morte está iminente, numa previsão de horas ou dias (agonia), e não se preveem intervenções agudas;

- Estável - nesta fase incluem-se os doentes que não estão em nenhuma das fases anteriores.

Há ainda a acrescentar uma $5^{\mathrm{a}}$ tipologia, específica, referente ao apoio prestado no luto. São os doentes em fase aguda de cuidados paliativos aqueles que podem justificar maior número de intervenções - terapêuticas e, eventualmente, diagnósticas - mais complexas (ANCP, 2006, p. 7).

Como integrante das equipes multiprofissionais de saúde, entre outras atribuições, caberá ao(à) assistente social conduzir as relações entre usuários que apresentem indicação para tratamento com CPs, familiares e demais membros da equipe de saúde, potencializando a perspectiva do direito, seja no que concerne à qualidade de vida, seja no respeito às suas crenças e vontades relacionadas à condução do seu tratamento e da sua vida.

Para garantir uma melhor sistematização das ações e atribuições profissionais em saúde relativas à organização e execução de cuidados paliativos, em 2013, foram construídas em conjunto pela Associação Europeia de Cuidados Paliativos, Associação Internacional de Cuidados Paliativos, Aliança Mundial de Cuidados Paliativos e pelo Observatório dos Direitos 


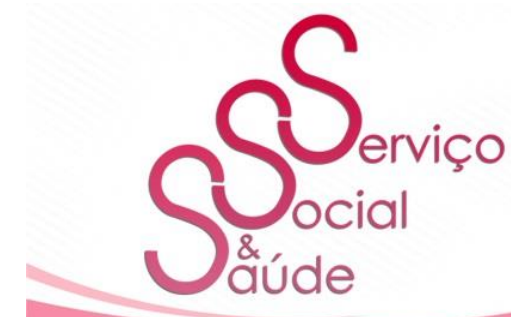

ISSN 2446-5992

(1) (1) (-)

doi: $10.20396 /$ sss.v18i0.8656828

Humanos, uma série de prerrogativas incluídas na "Carta de Praga", conferindo os CPs como direito humano e uma obrigação legal reconhecida pelas convenções da Organização das Nações Unidas (ONU), cuja rede de saúde deve ser garantida pelo Estado. Entretanto, apesar desse reconhecimento, a sua implementação e oferta nem são observadas em vários países, nem na totalidade dos serviços de saúde entre os países que os desenvolvem (EAPC, 2013).

Quando se opta pela aplicação dos CPs, o foco sai da órbita da cura da doença e se volta para as necessidades físicas, espirituais, psicológicas de usuários e seus familiares (MACIEL, 2008).

A OMS recomenda que os cuidados paliativos sejam integrados ao plano terapêutico desde o diagnóstico, com ênfase no controle dos sintomas e na promoção da qualidade de vida ativa e autônoma. É indicado expandir o campo de atuação desde a evolução natural da doença até o favorecimento de uma morte digna, no local de escolha do paciente, através de uma abordagem multidisciplinar, que inclui as dimensões psicossociais e espirituais do ser humano. Nessa abordagem, os familiares e cuidadores são incluídos e assistidos enquanto dimensão essencial do tratamento e acompanhados em seu luto também após a morte do paciente (OMS, 2014 apud UGARTE, 2014, p. 18).

A questão dos cuidados paliativos se inseriu nos debates nacionais a partir da década de 1980, quando o país passou por reorganização social, democrática, política e econômica que influenciou diretamente a construção de uma rede de serviços onde os cuidados paliativos passaram a ser oferecidos, cujas primeiras iniciativas localizaram-se nos Estados do Rio Grande do Sul, São Paulo e Santa Catarina e foram ampliadas a partir dos anos 2000 em todo o território nacional (NICKEL et al., 2012). Todavia, o Brasil está entre os países onde os CPs acontecem de maneira incipiente e variada de acordo com a Rede Estadual e Municipal, com serviços desarticulados, concentrados em algumas regiões, com casos em que postos funcionam sem protocolos ou manuais voltados especificamente para a realização de CPs (ANDRADE, 2007; MACIEL 2008).

Mesmo com um desenvolvimento ainda muito lento e assistemático foram editadas no país algumas portarias ministeriais que trouxeram os cuidados paliativos como forma de conduzir os tratamentos de saúde, a exemplo da Portaria GM/MS n 19 , de 03 de janeiro de 


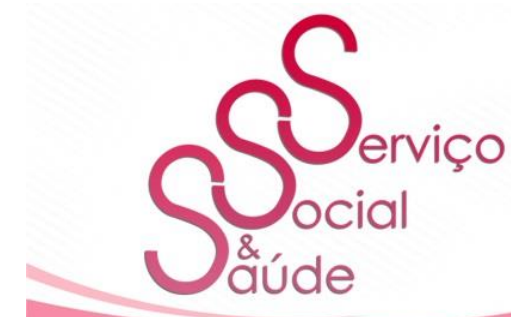

ISSN 2446-5992

(c) (1)(2)

doi: 10.20396/sss.v18i0.8656828

2002, que instituiu o Programa Nacional de Assistência à Dor e Cuidados Paliativos. Além desta, foi emitida a Portaria GM/MS n² 2.439, de 8 de dezembro de 2005 - retificada pela Portaria No 874, de 16 de Maio de 2013 - que instituiu a Política Nacional para a Prevenção e Controle do Câncer na Rede de Atenção à Saúde das Pessoas com Doenças Crônicas no âmbito do Sistema Único de Saúde (SUS), ambas indicando os Cuidados Paliativos (CPs) como alternativa de tratamento.

A existência dessas portarias indica que os CPs precisam ser vistos como ação do direito integral à saúde, a serem acessados nos âmbitos macro e micro, respeitando-se as determinações do processo saúde-doença e não apenas desenvolvidos sob a forma de tratamentos complementares (SILVA; SILVEIRA, 2015). No entanto, a maioria das ações de CPs realizadas no Brasil ainda é feita isoladamente por equipes na Atenção Básica, em serviços domiciliares ou hospitalares (WRIGHT et al. apud UGARTE, 2014).

Em oposição a esse isolamento, os CPs precisam ser reconhecidos como ações ou serviços contínuos da Rede de Saúde, a serem efetivados de maneira integral e universalizada, mesmo que isto represente um desafio para a gestão do SUS, tendo em vista o aumento da expectativa de vida da população e a expansão de doenças crônicas que explicitaram a demanda por CPs como parte inerente aos serviços de saúde (SILVA; SILVEIRA, 2015).

Entre os princípios do SUS, destaca-se a congruência entre a integralidade e a estratégia terapêutica dos CPs, pois aquela propõe um atendimento integral e ampliado dos usuários nos serviços que compõem a rede, mediante sua organização contínua e interligada, a partir do que o usuário possa ter total assistência de suas necessidades, o que exige a abrangência do diálogo entre os diferentes sujeitos que desenvolvem o sistema de saúde (SILVA; RAMOS, 2010; FRACOLLI et al., 2011). Do mesmo modo, os CPs devem ser dirigidos aos pacientes, seus familiares e à comunidade, ao passo em que abordam os distintos problemas que estão associados à doença e que ameaçam a vida ou conduzem ao sofrimento e, portanto, encontramse distantes de uma abordagem isolada e centrada em apenas um aspecto da doença, embora devam proporcionar o atendimento das necessidades individuais dos pacientes (EAPC, 2013) e é neste sentido que a Associação Europeia de Cuidados Paliativos (EAPC) recomendou na 


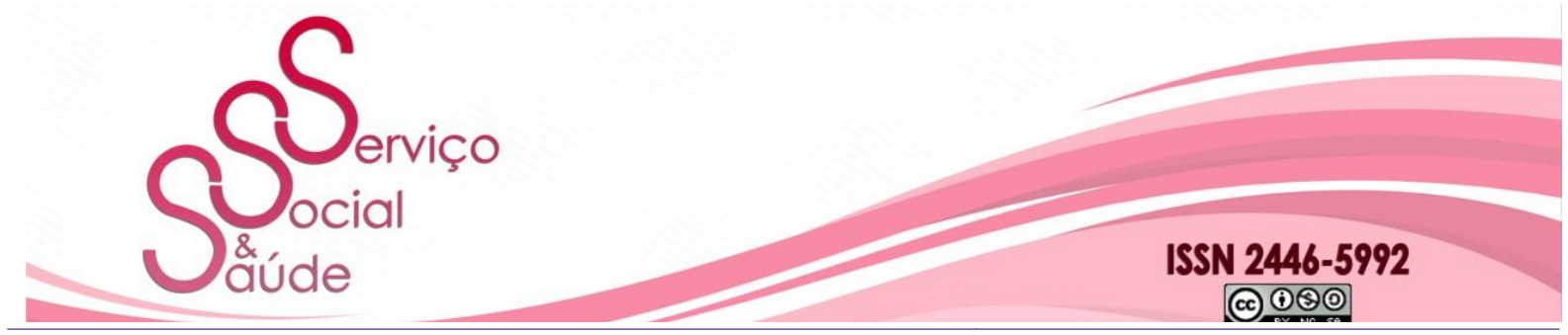

doi: $10.20396 /$ sss.v18i0.8656828

Carta de Praga que os governos desenvolvam políticas globais de saúde que integrem os CPs aos demais serviços de saúde, assegurando assistência médica, farmacológica e psicológica a pacientes e familiares desde a prestação de cuidados aos primeiros até após sua morte no que concerne aos últimos.

Defende-se, portanto, que os cuidados paliativos sejam desenvolvidos sob a lógica do direito nos ambientes em que a produção do cuidado em saúde é realizada. Dentre estes ambientes, este artigo se volta para a realização dos CPs em Unidades de Terapia Intensiva (UTI), tomando como parâmetro a realidade vislumbrada no Hospital Universitário Lauro Wanderley (HULW), vinculado à Universidade Federal da Paraíba (UFPB). A opção pela UTI se deu porque é um ambiente restrito, com uso de alta complexidade tecnológica (ZACARIAS et al., 2009), mas que não prescinde da filosofia ou da terapêutica dos cuidados paliativos que nesse ambiente possui entre seus objetivos prestar uma morte digna e tranquila ao paciente sem prognóstico de cura, reduzir o sofrimento de usuários e familiares, e permitir que a conduta terapêutica respeite as decisões dos usuários e de sua autonomia, ou, nos casos em que estes não podem manifestá-las, que sejam ouvidos os familiares ou representantes legais, não obstante o acompanhamento permanente de equipe multiprofissional (MORITZ et al., 2008).

Embora os benefícios da aplicação dos CPs não se resumam aos cuidados em fim de vida (EAPC, 2013), em pacientes na UTI, aqueles tanto afirmam a vida, quanto consideram a morte como parte de um processo natural, o que conflui para a ratificação da importância da experiência de vida de cada usuário, mas também para a opção pela não adoção de condutas terapêuticas que sejam desnecessárias ou que estendam seu sofrimento e degradação física e/ou psíquica (MORITZ et al., 2008).

\section{A INTERVENÇÃO DE ASSISTENTES SOCIAIS EM CUIDADOS PALIATIVOS}

A ampliação do conceito de saúde fez com que "O discurso do reconhecimento da saúde como um direito social e um dever do Estado ultrapassasse uma abordagem limitada e centrada em um discurso acrítico e normativo" (NOGUEIRA; MIOTO, 2006, p. 223). 


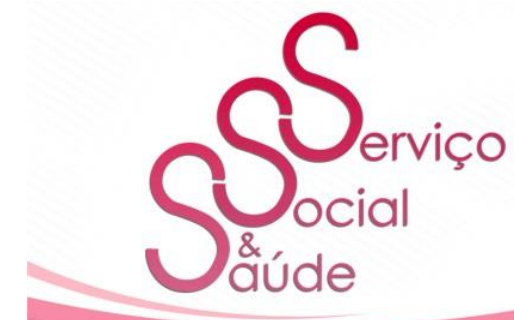

ISSN 2446-5992

(c) (1) (3)

doi: $10.20396 /$ sss.v18i0.8656828

Tal conceito possibilitou ao(à) assistente social a ampliação de seus espaços sócioocupacionais na saúde, cuja atuação é reconhecida tanto no plano legal quanto social (MIOTO; NOGUEIRA, 2009), e como os cuidados paliativos são realizados a partir de uma perspectiva multiprofissional, o(a) assistente social, enquanto trabalhador(a) da saúde, também integra as equipes que realizam essa estratégia.

Segundo Mioto e Nogueira (2009) os(as) assistentes sociais apresentam três determinações no desenvolvimento de suas práticas profissionais, quais sejam: necessidades sociais em saúde; direito à saúde e produção da saúde, ainda que seu trabalho seja atravessado por várias dicotomias, dentre as quais estão os projetos em disputa na área da saúde - o da Reforma Sanitária e o privatista (BRAVO; MATOS, 2006).

As demandas postas ao(à) assistente social por cada um destes projetos são antagônicas, uma vez que no privatista, aquelas se voltam para o incentivo de ações fiscalizadoras e seleção de usuários, com predomínio de práticas individuais em detrimento da universalidade e integralidade. Já o projeto da Reforma Sanitária defende ações baseadas na democratização dos serviços de saúde e do acesso, com controle social e trabalho multiprofissional, este último mais compatível com as propostas e diretrizes previstas no Projeto Ético-Político do Serviço Social, voltadas para ações com qualidade, em equipe, direcionadas à democratização dos serviços e ao respeito aos usuários (CFESS, 2010).

Em termos gerais, ao compor a equipe multiprofissional responsável pelos cuidados paliativos, o(a) assistente social será responsável pelas orientações a usuários, familiares, pela integração entre estes e a equipe e pela rede de suporte social (ANDRADE, 2012).

O atendimento direto aos usuários faz parte da atuação do(a) assistente social no âmbito da saúde com predomínio de ações socioassistenciais, socioeducativas e interdisciplinares, muitas vezes interligadas entre si, integrando um atendimento em rede (CFESS, 2010).

A atuação do(a) assistente social junto aos usuários assistidos com CPs e também junto aos seus familiares inicia-se pelo ouvir, a partir do que se estabelece um vínculo que norteará as ações que esse(a) profissional desempenhará, possibilitando-lhe atender as necessidades e demandas sociais daqueles (SIMÃO et al., 2010). 


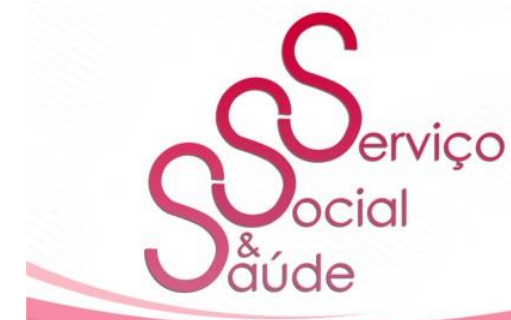

ISSN 2446-5992

(c) 10 (3)

doi: $10.20396 /$ sss.v18i0.8656828

Neste sentido, a escuta e o acolhimento serão os pilares para o início das abordagens que o(a) assistente social desenvolverá, pois essas ações são imprescindíveis para o reconhecimento do momento ideal e do tempo necessário para cada ação de trabalho, ambos determinantes para que cada atividade seja realizada de maneira adequada, configurando sempre o respeito pelo usuário e seus familiares (ANDRADE, 2012).

Segundo Simão et al. (2010) o(a) assistente social e os demais membros da equipe multiprofissional são responsáveis pelo fortalecimento do sistema de apoio ao usuário - de modo a evitar que este desenvolva sentimentos de abandono -, e pela valorização das suas escolhas - no intuito de dirimir a sensação de limitação e dependência -, cabendo ao(à) assistente social o papel de mediador(a) entre usuário/familiares/equipe (ANDRADE, 2012).

Todavia, apesar de integrar as equipes que trabalham com CPs, o(a) assistente social muitas vezes enfrenta a falta de clareza dos demais profissionais acerca de suas reais atribuições e competências (CFESS, 2010) que somada ao baixo conhecimento pelas equipes acerca dos princípios norteadores básicos para o trabalho com CPs e ao incipiente preparo na formação profissional do(a) assistente social para essa intervenção, resultam em práticas imediatistas, fragmentadas e de baixa qualidade para usuários e familiares.

Cabe destacar que em muitas situações, as equipes remetem críticas à ausência de protocolos voltados aos CPs que justificariam as dificuldades encontradas no cotidiano profissional, contudo Matsumoto (2012, p. 26) assevera a este respeito que:

O Cuidado Paliativo não se baseia em protocolos, mas sim em princípios. Não se fala mais em terminalidade, mas em doença que ameaça a vida. Indica-se o cuidado desde o diagnóstico, expandindo nosso campo de atuação. Não falaremos também em impossibilidade de cura, mas na possibilidade ou não de tratamento modificador da doença, desta forma afastando a ideia de "não ter mais nada a fazer". Pela primeira vez, uma abordagem inclui a espiritualidade dentre as dimensões do ser humano. A família é lembrada, portanto assistida também após a morte do paciente, no período de luto.

Portanto, pensar os cuidados paliativos a partir de princípios requer mais que o domínio ou o esclarecimento de protocolos, pressupõe a compreensão do que eles efetivamente são e do que se pretende alcançar junto a usuários e familiares com a sua aplicação, o que exige uma 


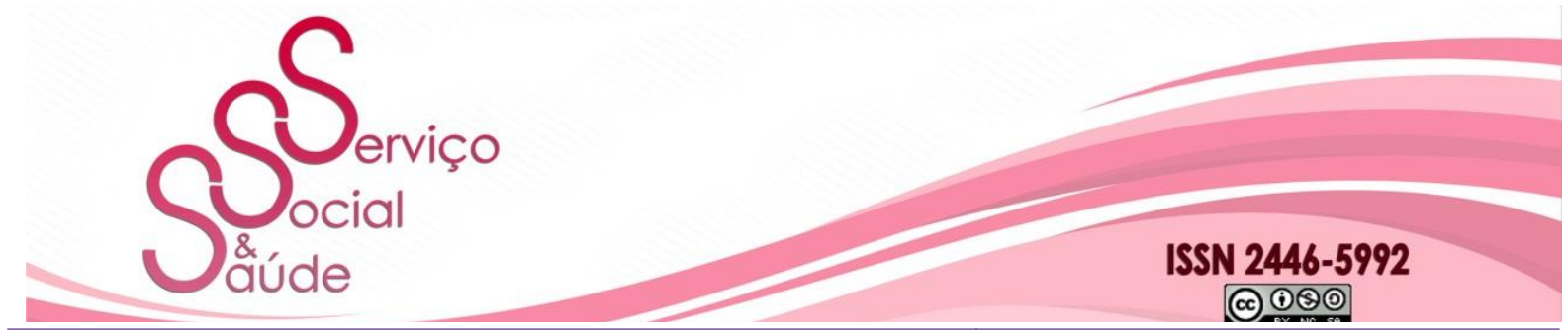

doi: $10.20396 /$ sss.v18i0.8656828

intervenção integral e humanizada. Neste sentido, de acordo com Neto (2000 apud ROMÃO, 2012), os profissionais que atuam com CPs devem possuir um perfil com características como flexibilidade, idealismo, capacidade de enfrentamento de frustrações, e abertura ao outro e às diferenças.

\section{MÉTODO}

Este estudo possui caráter exploratório e de campo e foi realizado no Hospital Universitário Lauro Wanderley (HULW) junto ao núcleo profissional de Serviço Social e às Residentes de Serviço Social, entre os meses de agosto e dezembro de 2016, seguindo os preceitos da Resolução 466/2012 do CNS, com pesquisa aprovada pelo Comitê de Ética do HULW (número 57133916.5.0000.5183).

A amostra utilizada foi definida por critérios de acessibilidade, assim, do universo de 20 (vinte) assistentes sociais que compunham à época a equipe de Serviço Social do HULW, extraiu-se uma amostra de $80 \%$ (16) profissionais. Em relação às Residentes de Serviço Social, de um universo de 6 (seis) profissionais, extraiu-se uma amostra de 5 residentes. A partir disto, a amostra foi subdividida em dois grupos, quais sejam: o primeiro correspondente às assistentes sociais e Residentes que atuam na UTI e o segundo grupo composto por profissionais e Residentes que atuam nas demais clínicas e ambulatórios do HULW.

Quanto aos instrumentos de coleta de dados utilizados na pesquisa, recorreu-se à aplicação de questionário (que continha quatro questões objetivas e dez subjetivas), bem como um levantamento bibliográfico. Após a coleta dos dados primários, as respostas das questões objetivas foram organizadas em tabelas e gráficos, enquanto que os dados qualitativos oriundos das questões subjetivas foram destacados em fragmentos, ambos analisados à luz do corpo teórico selecionado, relacionado às questões abordadas. 


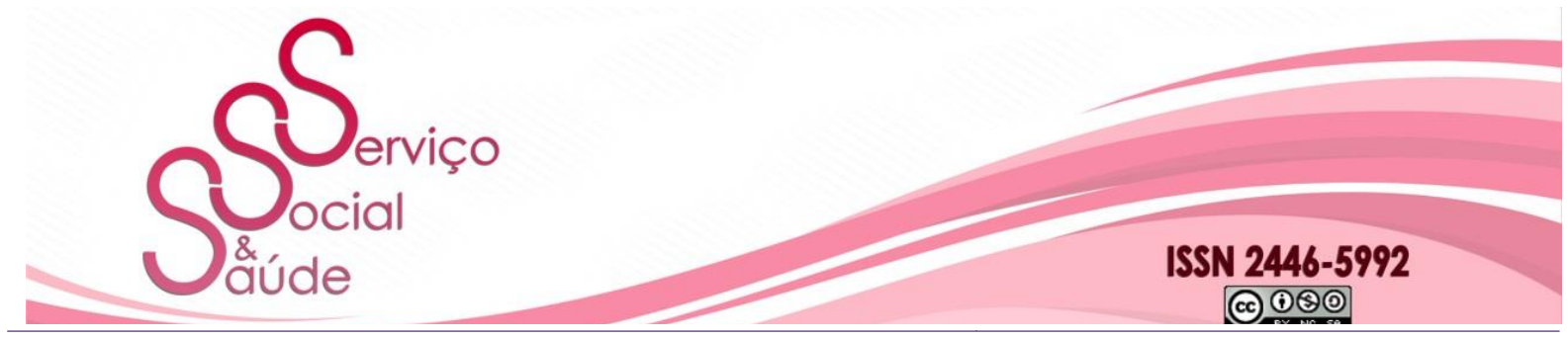

doi: $10.20396 /$ sss.v18i0.8656828

\section{RESULTADOS E DISCUSSÃO}

A presente sessão apresentará o processo de análise de dados referente à pesquisa realizada com o núcleo profissional de Serviço Social e Residentes de Serviço Social do HULW, verificando o conhecimento dos(as) assistentes sociais e Residentes de Serviço Social sobre os cuidados paliativos e apontando as principais ações profissionais do Serviço Social junto a usuários assistidos com CPs e seus familiares.

Em relação à amostra, todas as assistentes sociais e Residentes foram do gênero feminino fato que, segundo Veloso (2001 apud TIRBUTINO, 2015) ratifica a visão social do Serviço Social como uma profissão eminentemente feminina, o que se soma ao processo de "feminização" das profissões no âmbito da saúde (MATOS; TOASSI; OLIVEIRA, 2013) que, segundo os autores, é uma das tendências em foco no contexto desta política.

A Tabela 01 traz um demonstrativo dos dados relativos ao processo formativo das assistentes sociais e Residentes de Serviço Social.

Tabela 01: Formação Profissional de Assistentes Sociais e Residentes do HULW

\begin{tabular}{l|l|l|c}
\hline $\begin{array}{l}\text { Ano de Formação } \\
\text { das Assistentes } \\
\text { Sociais }\end{array}$ & $\mathrm{N}^{\mathbf{0}}$ & $\begin{array}{l}\text { Ano de Formação } \\
\text { das Residentes }\end{array}$ & $\mathrm{N}^{\mathbf{0}}$ \\
\hline $\mathbf{1 9 7 5}$ a 1979 & 2 & $\mathbf{1 9 7 5}$ a 1979 & 0 \\
\hline $\mathbf{1 9 8 0}$ a 1990 & 5 & $\mathbf{1 9 8 0}$ a 1990 & 0 \\
\hline $\mathbf{1 9 9 1}$ a 2000 & 5 & $\mathbf{1 9 9 1}$ a 2000 & 0 \\
\hline $\mathbf{2 0 0 1}$ a 2011 & 4 & $\mathbf{2 0 0 1}$ a 2011 & 4 \\
\hline Após 2012 & 0 & Após 2012 & 1 \\
\hline
\end{tabular}

Fonte: Dados primários (João Pessoa-PB, 2016)

A variedade dos anos de formação observada na Tabela 01 demonstra diversificação do perfil do conjunto de assistentes sociais e Residentes, com formações heterogêneas (fruto de várias reformas curriculares) que concorreram para múltiplas apropriações das modificações operadas pelo movimento crítico da profissão ao longo dos anos e das transformações da realidade nacional e da política de saúde brasileira. 


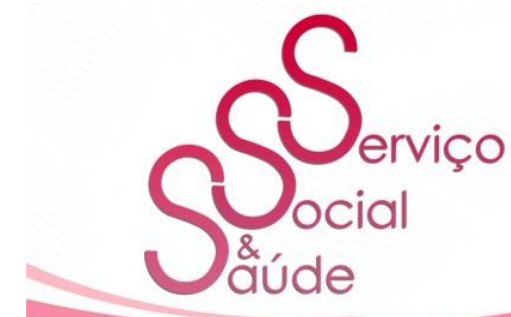

ISSN $2446-5992$

(c) (1) (3)

doi: $10.20396 /$ sss.v18i0.8656828

Visando um exame mais apurado dos dados relacionados diretamente ao tema do estudo, optou-se por organizá-los em eixos temáticos, mantendo-se a divisão entre os grupos das assistentes sociais e Residentes que atuam na UTI e das profissionais e Residentes que integram as demais clínicas e os ambulatórios do HULW.

\section{EIXO A: PERCEPÇÃO DAS ENTREVISTADAS SOBRE CUIDADOS PALIATIVOS}

Tomando-se por base a definição de Matsumoto (2012) acerca da aplicação dos cuidados paliativos a partir de determinados princípios que pressupõem sua adequada compreensão, interpelou-se as entrevistadas do primeiro grupo sobre seu entendimento em relação aos CPs, com predominância de falas como as destacadas a seguir:

[...] eu entendo que são medidas que são tomadas no âmbito terapêutico para definir um tipo de assistência a ser dada ao paciente, de acordo com o que foi decidido pela equipe médica, se aquele paciente deve ou não estar dentro de critérios para o estabelecimento de Cuidados Paliativos. (Assistente Social 02).

De maneira geral, $[\ldots]$ no senso comum, eu percebo como uma maneira de proporcionar ao paciente uma morte digna, um final de vida digno, amenizando as dores, dando maior conforto, deixando a família próxima, fazer essa transição com o máximo possível de conforto, de afago, de dignidade, de amor. (Residente 01).

As falas supracitadas são representativas do grupo e demonstraram disparidade na compreensão acerca dos CPs, cujo ponto em comum residiu em uma visão limitada à sua vinculação com cuidados destinados a pacientes em estado terminal, bem como dependência da equipe multiprofissional ao médico, reforçando a centralização deste saber, em detrimento de uma visão holística e integral do paciente e não apenas da doença. Isto se confronta com a perspectiva da Sociedade Brasileira de Geriatria e Gerontologia (SBGG) que pressupõe que os CPs também devem incorporar as dimensões preventiva e promocional, no que se refere a novos problemas, bem como oportunizar o desenvolvimento de experiências voltadas ao crescimento pessoal, espiritual e de autorrealização do paciente (SBGG, 2014). 


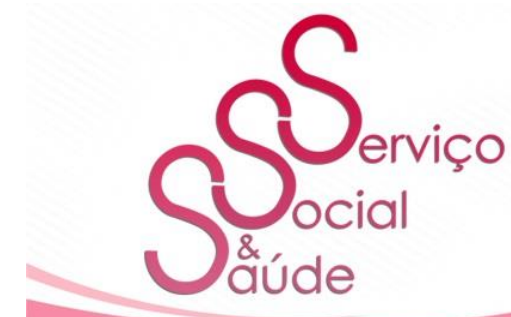

ISSN 2446-5992

(ㅇ) 100

doi: $10.20396 /$ sss.v18i0.8656828

Ressalta-se que, se de um lado, essas falas remontaram ao princípio propagado pela Organização Mundial da Saúde (OMS) que previu o uso dos CPs para a promoção do alívio da dor e de outros sintomas em pacientes em estado terminal ou que se encontram em quadro irremissível e em declínio progressivo, de outro, ao focarem na doença e na morte, isolaram esse princípio dos demais, como a afirmação da vida e a busca pela construção de ações que deem suporte a uma vida tão ativa quanto possível (MATSUMOTO, 2012). Tal compreensão ampliada foi observada nas falas do segundo grupo de que são representativas estas apresentadas abaixo:

[...] vêm para atender os usuários, os pacientes que estão em uma situação de doença $[. .$.$] que não tem cura, que sabe-se que ele vai chegar à morte, mas que$ ele chegue à morte com os cuidados sem sofrimento, com uma qualidade de vida [...], mas com todos os cuidados que ele merece ter dentro do que ele pode receber, aliviar aquele sofrimento. (Assistente Social 09).

Entendo que são cuidados que fazem parte, que são cuidados voltados para usuários que não têm prognóstico de cura, que são usuários que vão manter uma condição de saúde, então são cuidados voltados para que a qualidade de vida desses usuários seja melhor, seja mais qualificada [...]. (Residente 02).

Observou-se que as falas do segundo grupo voltaram-se mais para uma perspectiva de bem-estar e qualidade de vida que, segundo a OMS (1986 apud MATSUMOTO, 2012), não se refere apenas à saúde, mas também ao acesso a serviços, medicamentos e outras questões que podem influenciar na vida do paciente. Entretanto, embora mais qualificadas, essas falas ainda não sinalizaram para os CPs como integrantes dos três níveis de atenção à saúde, a partir do que seu significado seria ampliado, garantido como direito integral, equânime e universal, conforme advertem Mendes e Vasconcellos (2015).

\section{EIXO B: EXERCÍCIO PROFISSIONAL DE ASSISTENTES SOCIAIS COM CUIDADOS PALIATIVOS}

A partir do que foi exposto anteriormente, considerou-se necessário analisar qual a ocorrência de trabalho com cuidados paliativos nos setores de atuação dos dois grupos investigados. No primeiro grupo, apesar de as assistentes sociais e Residentes atuarem na UTI 


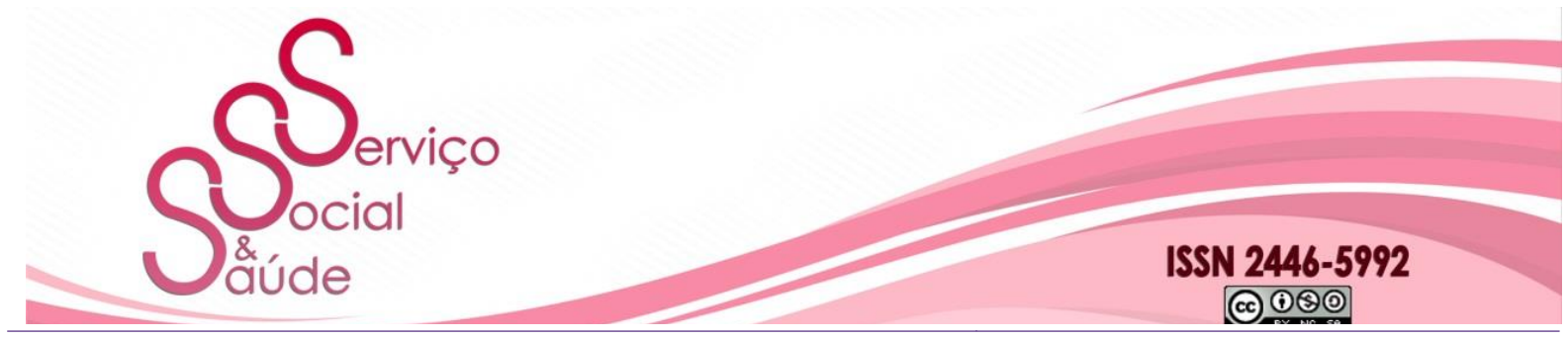

doi: $10.20396 /$ sss.v18i0.8656828

- setor que no ambiente hospitalar possui maior incidência de pacientes sobre os quais os CPs são aplicados - constatou-se que $67 \%$ das entrevistadas nunca realizaram cuidados paliativos, o que demonstrou fragilidade no desenvolvimento desta estratégia no referido local.

A título de esclarecimento, destacaram-se duas falas que sinalizaram opiniões sobre a atuação do Serviço Social nesse campo de atuação:

A gente tá iniciando agora uma Comissão de Cuidados Paliativos no hospital há pouco tempo, uns dois meses e lá na UTI tá acontecendo deles solicitarem a intervenção do geriatra que tem essa especialização - especialidade em Cuidados Paliativos - e ele faz uma conversa com a família junto com o Serviço Social e a Psicologia. E na parte do Serviço Social, a gente tenta dar continuidade de uma primeira intervenção que geralmente é do médico, ele explica a parte clínica e a gente tenta dar esse apoio à família junto com a Psicologia. E tentando entender a situação social da família, às vezes a família quer manter o paciente vivo a todo custo por causa de renda, aí a gente tenta confortar a família, porque os cuidados paliativos não só são com os pacientes são também com a família. (Assistente Social 01).

Atualmente eu estou na coordenação do Serviço Social, estive na UTI que foi onde eu tive a primeira aproximação com essa temática, [...] essa aproximação não se deu no âmbito teórico, mas sim na necessidade do serviço que foi na UTI. (Assistente Social 02).

Em termos gerais, as falas do primeiro grupo indicaram que a prática dos CPs na UTI ainda é algo que está iniciando, apesar de as primeiras experiências com CPs no Brasil datarem dos anos 1980 e 1990 (MATSUMOTO, 2012), não sendo concebidos como uma prática contínua, como alertaram Barros et al. (2012), cujos profissionais muitas vezes somente se depararam com a temática na prática (HERMES; LAMARCA, 2013).

A ausência de intervenção com cuidados paliativos pelas profissionais de Serviço Social foi reiterada também no segundo grupo, quando $69 \%$ das entrevistadas sinalizaram que não atuaram com os CPs nos seus setores de trabalho. Todavia, como nas demais clínicas do HULW e no Ambulatório há serviços destinados a pacientes com doenças crônicas e irreversíveis, 19\% afirmaram que já trabalharam com CPs. Por sua vez, a incompreensão sobre o que são as atribuições dos(as) assistentes sociais em CPs foi revelada quando $12 \%$ das profissionais não souberam responder. 


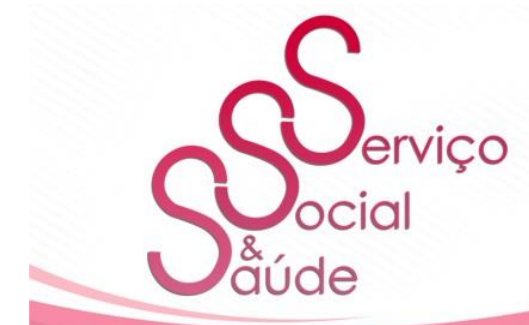

ISSN 2446-5992

(๑) $\odot \odot$

doi: $10.20396 /$ sss.v18i0.8656828

Entre os depoimentos, houve questões levantadas que apontavam para a impossibilidade de desenvolver CPs em decorrência da ausência de trabalho em equipe multiprofissional e também pela resistência das famílias, conforme demonstrado a seguir:

Não, porque eu acho que é um trabalho em equipe que eu sonho com essa equipe, mas que eu não posso atuar sozinho tem que ser um trabalho em conjunto, que todos participem. (Assistente Social 04).

Quando nós temos um paciente que está com indicação, que a família já aceitou, todo mundo já sabe, aí é possível fazer isso, quando não, não tem como. (Residente 01).

Apesar de parte dos relatos das entrevistadas apontarem para questões alheias ao Serviço Social, como supramencionado, há também que se considerar que a análise dos fragmentos de fala em ambos os grupos apontou igualmente para uma baixa clareza sobre quais as demandas relativas ao CPs e que ações deveriam ser acionadas para respondê-las. Nessa direção é importante apontar que:

A atuação do assistente social em equipes de atenção paliativa pode ser resumida em: conhecer paciente, família e cuidadores nos aspectos socioeconômicos, visando ao oferecimento de informações e orientações legais, burocráticas e de direitos, imprescindíveis para o bom andamento do cuidado ao paciente, e para a garantia de morte digna. Cabe a esse profissional também avaliar a rede de suporte social dos envolvidos, para junto a estes acioná-la em situações apropriadas; conhecer e estabelecer uma rede intrainstitucional, no intuito de garantir atendimento preciso ao paciente, além de constituir-se como interlocutor entre paciente/família e equipe nas questões relacionadas aos aspectos culturais e sociais que envolvem o cuidado de forma geral (ANDRADE, 2012a, p. 221).

O desconhecimento ou baixo esclarecimento não apenas fragiliza os CPs no ambiente hospitalar, mas corrobora para que os usuários que se encontram internos neste serviço não sejam assistidos por tratamentos que sejam condizentes com a sua realidade de saúde (MENDES; VASCONCELLOS, 2015).

Pensando na oferta de CPs sob uma lógica de integralidade dos serviços, ao se verificar que isto ainda é pontual, Rabello e Rodrigues (2010) testificam que, embora mormente sua oferta se dê no ambiente hospitalar, nem sempre ele é o local mais adequado a usuários e 


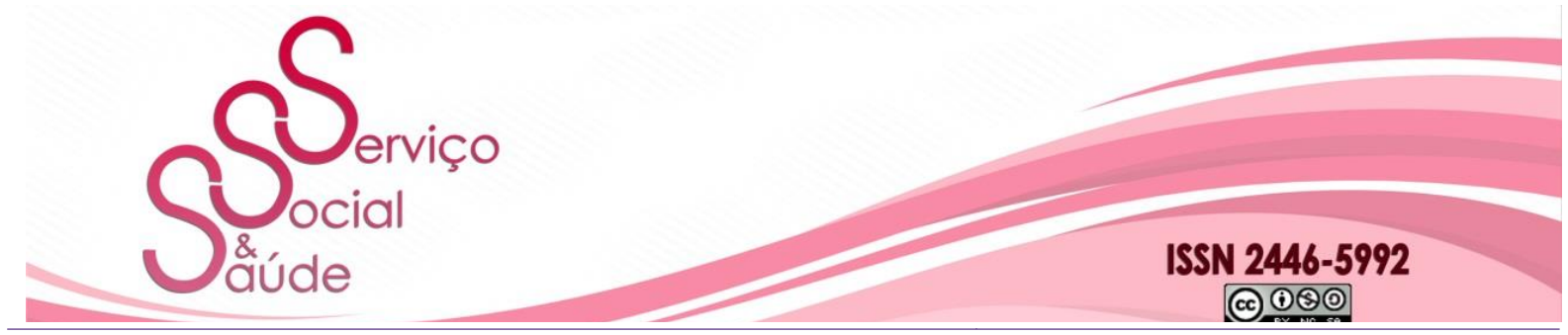

doi: $10.20396 /$ sss.v18i0.8656828

familiares, pois pode concorrer para sobrecargas de ordem financeira, emocional, social, e menor autonomia daqueles.

Especificamente em relação ao trabalho do(a) assistente social em CPs, para além dos aspectos socioeconômicos, ético-políticos, dos processos de orientação e acolhimento, de sua atuação na equipe, da necessidade de conhecimento para avaliação e indicação de prioridades relacionadas às suas competências profissionais, também é possível que assuma funções de coordenação e treinamento, seja de equipes de voluntários, seja de profissionais que atuam direta ou indiretamente com CPs, bem como dinamizar ações e projetos de humanização no setor hospitalar, bem como estratégias e metodologias de trabalho gerais que possam ser particularizadas nos diversos casos individuais.

Em decorrência da imagem historicamente constituída na profissão, é comum que usuários e familiares recorram ao Serviço Social em busca de conforto, acolhida, escuta, mas, embora sejam parte da perspectiva de uma atuação humanizada, o(a) assistente social precisará ir além da órbita do apoio e da escuta, o que lhe exigirá saber distinguir a prática tradicional da socioeducativa, de modo a evitar incorrer em práticas terapêuticas alheias ao seu atual Projeto Ético-Político Profissional (PEPP).

Entre as possibilidades de intervenção desse(a) profissional destacam-se: a "solução de problemas, ausência de preconceito" vinculadas à "realização pessoal”; a "conquista do respeito dos outros" e o "respeito aos outros" no que concerne à "estima"; e a "segurança do corpo, do emprego, de recursos, da moralidade, da família, da saúde, da propriedade” (SBGG, 2014, p. 9). Em relação às necessidades do paciente e de sua família, consideram-se como prioritárias para o Serviço Social as ações vinculadas aos domínios: “cuidados ao fim da vida / processo de morrer" e "social", inclusive durante os processos de internação hospitalar (SBGG, 2014, p. $11)$.

Para tanto, será necessário ao(à) assistente social fazer inicialmente o levantamento da avaliação socioeconômica para que possa proceder ao atendimento social. Neste sentido, a avalição social deverá compreender: composição familiar, local de moradia, formação, profissão e situação empregatícia do paciente, renda familiar, religião e rede de suporte social. 


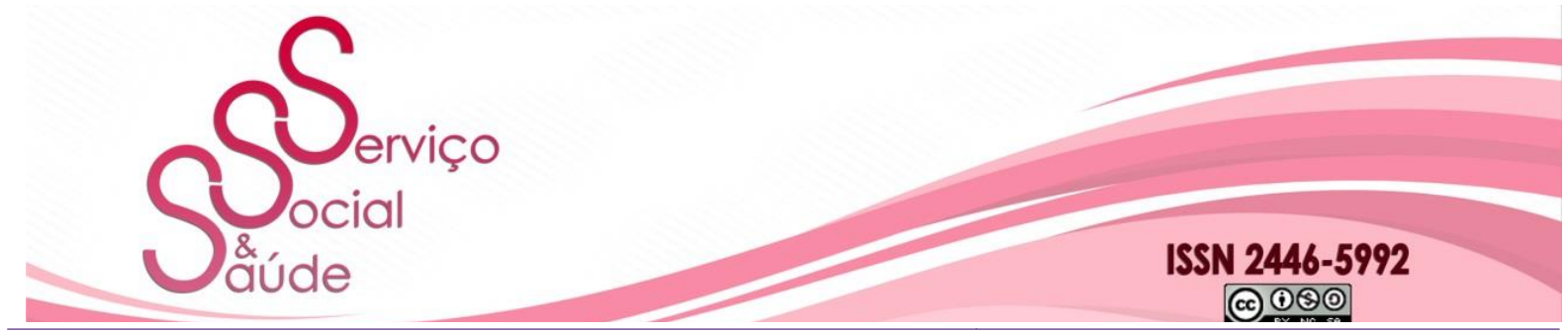

doi: $10.20396 /$ sss.v18i0.8656828

Estes aspectos compreendem desde a identificação da existência ou não de um cuidador, da rede de suporte social e consequentemente das dificuldades ou facilidades para os procedimentos necessários ao longo do tratamento, da situação econômica do paciente e de sua família, até sua religião que auxiliará na abordagem sobre a morte. Assim, são informações que se voltam a ações presentes, mas também futuras, permitindo ao(à) profissional a organização de um cenário de intervenção junto ao paciente e seus familiares (ANDRADE, 2012a).

Aliada a esta avaliação, caberá ao(à) assistente social o conhecimento dos recursos e objetivos institucionais e a rede de serviços a que o hospital está integrado para ampliação da possibilidade de cuidado, voltando tanto para a qualidade de vida e a morte digna do paciente, quanto para a manutenção e o equilíbrio familiar (ANDRADE, 2012a; 2012b).

Em relação à família, cabe ao(à) assistente social não apenas a minimização do sofrimento, mas também a orientação sobre questões legais e/ou burocráticas - guarda e/ou registro de filhos, testamentos, regularização de uniões, obtenção de tutelas e curatelas, dentre outros - que podem ser transmitidas individualmente ou em reuniões de família, cujas necessidades serão avaliadas em conjunto pela equipe (ANDRADE, 2012b).

Ainda quanto às famílias, é possível ao(à) assistente social observar e identificar possíveis casos de negligência, violência e exploração econômica de usuários, ou mesmo adoecimento de cuidadores, a necessidade de inserção daquelas em rede de proteção social e ainda, em conjunto com psicólogos e a equipe médica, a abordagem da morte e do luto que não podem ser ignorados entre pacientes submetidos aos CPs.

Todas estas ações implicam a necessidade de conhecimento, atualização das discussões em torno dos CPs e, sobretudo, planejamento das atividades, com previsão de ações a serem realizadas e registro do que foi alcançado e das estratégias do Serviço Social e da equipe multiprofissional. 


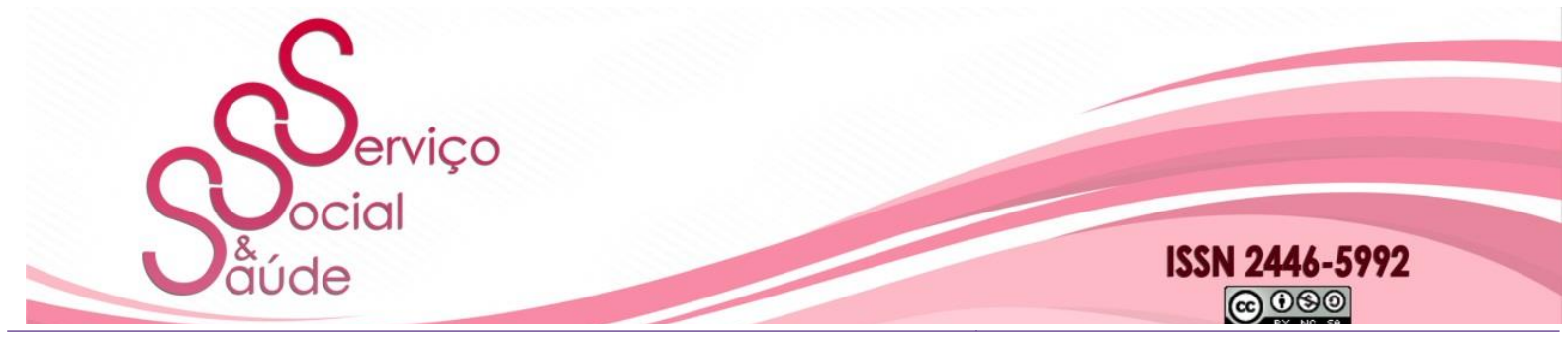

doi: $10.20396 /$ sss.v18i0.8656828

EIXO C: REPASSE DE INFORMAÇÕES SOBRE CUIDADOS PALIATIVOS NA FORMAÇÃO

PROFISSIONAL

Em todo este trabalho defendeu-se a necessidade de conhecimento dos CPs para sua adequada aplicação e, para tanto, há que se considerar a relevância do ambiente de formação dos(as) discentes de Serviço Social no estudo sobre a temática, embora se reconheça que ela ainda é pouco abordada na graduação, e incipiente nas pós-graduações em saúde.

Tal situação se comprovou entre as entrevistadas quando $100 \%$ das que compuseram o primeiro grupo afirmaram não ter recebido informações sobre os CPs no processo formativo, o que foi ratificado por $94 \%$ das entrevistadas do segundo grupo, fato observado por Simão et al. (2010) que advertiram que os(as) assistentes sociais ingressam na área de saúde com pouca ou nenhuma experiência ou conhecimento adquirido na graduação relativo aos CPS.

Para Figueiredo (2006 apud HERMES; LAMARCA, 2013) como os CPs ocorrem de forma lenta no país, os cursos de graduação ainda não apresentam em seus componentes curriculares uma discussão que os inclua, fazendo com que ocorra um déficit no processo de aprendizagem, o que dificulta o trabalho das equipes multiprofissionais de maneira geral.

Neste sentido, ao se considerar que na atuação profissional do(a) assistente social são mobilizados conhecimentos, saberes, práticas e o uso adequado de instrumentais em distintas políticas e áreas, para uma intervenção de qualidade com CPs, é mister a interligação dos saberes teóricos aos práticos (MARTINELLI, 2007), o que impõe a urgência da discussão da inclusão dessa estratégia de saúde no ambiente formativo.

Ademais, a formação e o treinamento em cuidados paliativos em cursos de graduação e de pós-graduação configuram-se como um dos pilares propostos pela Organização Mundial da Saúde (OMS) para que aqueles possam ser oferecidos eficazmente na política de saúde (UGARTE, 2014).

Em relação especificamente às UTIs, o desenvolvimento tecnológico e a busca pela cura fizeram com que "[...] ações distanásicas e sofrimento físico, mental e espiritual tanto do paciente como de seus familiares" (CARVALHO; ARANTES, 2008, p. 179) integrassem o 


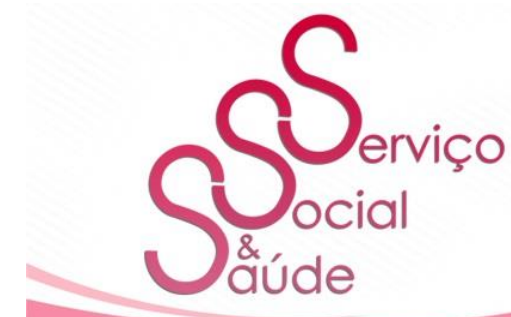

ISSN 2446-5992

(c) (1)(2)

doi: 10.20396/sss.v18i0.8656828

cotidiano desse ambiente, opondo-se à noção dos limites da luta pela vida, o que em parte poderia implicar em resistência ao trabalho com CPs. Aqui, mais uma vez a formação é um eixo essencial, pois, segundo os autores, com o estabelecimento de uma mudança cultural em favor da estruturação de CPs é possível paliar na UTI mesmo que não haja uma equipe designada especificamente para este trabalho no hospital, desde que exista formação específica da equipe que assiste o paciente (CARVALHO; ARANTES, 2008).

\section{EIXO D: MODOS DE REPLICAR AS INFORMAÇÕES SOBRE CUIDADOS PALIATIVOS NO SERVIÇO SOCIAL}

Uma vez verificada a quase total ausência de aproximação das entrevistadas em relação aos CPs durante seu processo de formação profissional, considerou-se importante investigar como os dois grupos receberam as informações sobre a temática.

Assim, embora as informações tenham sido repassadas de maneira distinta entre o primeiro grupo, a maioria sinalizou que esse repasse aconteceu dentro do local de trabalho, durante a sua prática profissional e a partir de necessidades advindas do próprio exercício, como destacado a seguir:

No serviço, atendendo alguns familiares de um paciente interno na UTI, essa discussão foi puxada pela equipe médica e veio para o Serviço Social para que a gente fizesse essa intermediação junto com a família, essa intermediação foi feita por meio de uma reunião multiprofissional. (Assistente Social 01).

[...] eu fui atrás porque aqui na UTI teve um caso que quase chegava a ser encaminhado para cuidados paliativos. (Residente 01).

Tal situação foi reafirmada no segundo grupo, com destaque para a busca individual e a troca de informações entre as profissionais, a partir das demandas cotidianas.

Internet, pesquisa pessoal mesmo, alguma coisa de revista informações que eu busquei. (Assistente Social 07).

No decorrer da assistência, em conversas informais de corredor, quando era notificado que algum paciente estava em cuidados paliativos. (Residente 04). 


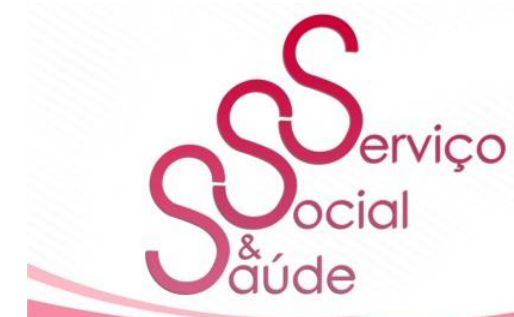

ISSN 2446-5992

(๑) $\odot \odot$

doi: $10.20396 /$ sss.v18i0.8656828

Os depoimentos revelaram não apenas uma ausência de discussão sobre os CPs no processo formativo e a necessidade de busca individual por informações que possam dinamizar o trabalho com CPs, mas apontaram tacitamente para a fragilidade sobre a sua compreensão e, sobretudo, objetivamente sobre o desconhecimento de como empreendê-los nas equipes de Serviço Social e junto aos demais profissionais de saúde, o que dificulta o trabalho nas equipes envolvidas com CPs (FIGUEIREDO, 2006 apud HERMES; LAMARCA, 2013) e pode corroborar para visões distorcidas e/ou simplistas dessa estratégia ou para ausência de sua oferta para usuários que deles necessitam.

\section{EiXo E: ARTiCULAÇÃo ENTRE O PROJETO ÉTICO-POLÍTiCO PROFISSIONAL DO SERVIÇO SOCIAL E O TRABALHO COM CUIDADOS PALIATIVOS}

As dimensões ético-política, técnico-operativa e teórico-metodológica oferecem direção à profissão, articulando-se em termos, poderes, fazeres e saberes na mediação das ações e práticas profissionais (MARTINELLI, 2007).

Além da necessidade do adequado desenvolvimento das dimensões técnico-operativa e teórico-metodológica pelos(as) assistentes sociais, este estudo radica-se na crença da congruência geral entre os princípios fundamentais que regem o Código de Ética do(a) Assistente Social - liberdade, defesa intransigente dos direitos humanos, cidadania, democracia, equidade e justiça social, respeito à diversidade, pluralismo, compromisso com a qualidade dos serviços e a competência profissional, articulação com as demais categorias, exercício sem discriminação, ou dominação de qualquer espécie (CFESS, 2012) - e as proposições da OMS que preveem, a partir do diagnóstico, a integração dos CPs ao plano terapêutico, com vistas à promoção da qualidade de vida ativa e com autonomia, o controle dos sintomas, a segurança de usuários e familiares em todas as etapas do adoecimento e o respeito às decisões tomadas por estes relativas ao final da vida (UGARTE, 2014). 


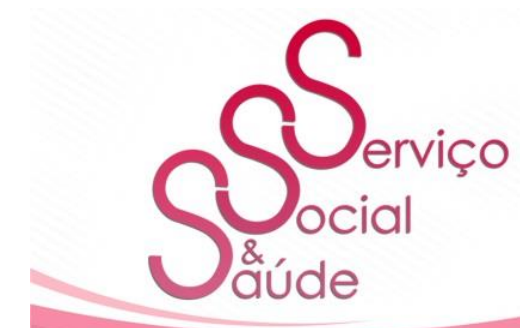

ISSN 2446-5992

(๑) $\odot \odot$

doi: $10.20396 /$ sss.v18i0.8656828

Neste sentido, buscou-se conhecer quais eram as opiniões das entrevistadas sobre a articulação entre o PEPP e os CPs, o que foi apontado de maneira geral, mas restrita quase especificamente ao Código de Ética do Assistente Social, como exemplifica a fala abaixo.

[...] eu acho que tem porque tem que ter para todas as ações, não só as de cuidados paliativos, a gente tem que se basear no Código de Ética, na autonomia da família, na questão do direito à liberdade que eles têm que ter como cidadãos, e mesmo o usuário, mesmo estando em estado de terminalidade, ele continua sendo cidadão, não vai deixar de ser por causa disso, a gente sempre fica conectando essa parte teórica e da legislação que fundamenta a profissão com a atuação do cotidiano. (Assistente Social 01).

Nas observações apresentadas pelo segundo grupo, permaneceu a compreensão de articulação ideal entre o PEPP e os CPs, mas também houve destaque para as limitações impostas pela realidade dos serviços que dificultam e/ou impedem que eles sejam ofertados por uma rede integral, como defendido pela OMS e Academia Nacional de Cuidados Paliativos (ANCP), e realizado no cotidiano profissional no HULW.

[...] com relação com ao Projeto Ético-Político, com certeza [...] tem a ver, porque o Projeto Ético-Político é um projeto guarda-chuva que ampara todas as ações [...] que são de garantia do direito do usuário, da garantia de melhorias de serviço e [...] eu estou envolvida nesse processo de desenvolvimento. (Assistente Social 10).

De certa forma é limitante porque se nós fomos pensar o nosso Projeto ÉticoPolítico é de defesa dos direitos, o momento que nós estamos passando é um momento muito frágil, de perda de direitos de limitação dos direitos, mas a própria profissão fica limitada porque se fosse pela nossa vontade, se não fossem as condições objetivas é claro que nós teríamos muito mais possibilidades de oferecer " $\mathrm{n}$ " coisas pros (sic) nossos pacientes, mas da mesma forma que nós não conseguimos articular uma ida dele pra casa, se for o desejo dele, porque a rede não tem estrutura pra (sic) isso, ele não pode receber esse cuidado em casa, ele fica preso ao hospital, então [...] não é por não ter a ver, é por não ter condições disso ser desenvolvido disso ser feito. (Residente 03).

O domínio e a articulação das dimensões que compõem a profissão são essenciais para que haja o controle e a aplicação de fundamento científico que os CPs exigem, de modo a evitar 


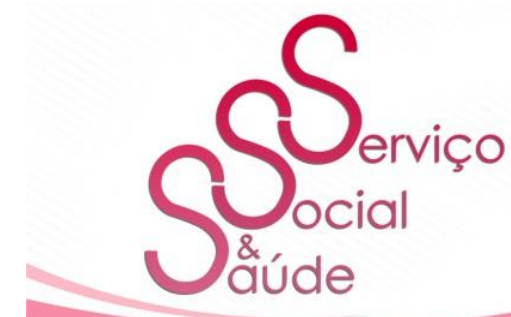

ISSN 2446-5992

(c) (1) (3)

doi: $10.20396 /$ sss.v18i0.8656828

que sejam "[...] confundidos com descaso, desatenção, ausência de assistência ou negligência". (MACIEL, 2008, p. 24). Assim, se os CPs devem ser organizados mediante trabalho multiprofissional, há que se ter em mente a existência de pré-requisitos para sua realização, tais como: consenso e clareza no estabelecimento dos objetivos e das estratégias; reconhecimento e valorização dos diversos saberes das distintas profissões que compõem as equipes; competência e comunicação entre cada profissional; coordenação competente; avaliação da efetividade e qualidade das ações empreendidas; e facilitação do processo de luto para familiares, amigos e a própria equipe de CPs (TAQUEMORI; SERA, 2008).

Ao compor as equipes que atuam com cuidados paliativos, o(a) assistente social deverá auxiliar na percepção das múltiplas necessidades dos usuários e seus familiares, inclusive reconhecendo as limitações e as possibilidades de cuidado pelos envolvidos, o que afasta a idealização da família que deve ser entendida na sua realidade e, embora cada família e paciente precisem ser vistos como únicos em suas particularidades, não se deve perder de vista o norte da universalidade, da liberdade, da democracia, do respeito ao usuário e da qualidade dos serviços que perpassam o PEPP, materializado pela realização de um exercício crítico e competente (MARTINELLI, 2007).

Dessa forma, se o tratamento com CPs se constitui “"...] em uma proposta de atenção ampla, consciente e organizada" (ANDRADE, 2008, p. 73), no âmbito do Serviço Social, uma atuação construída sob a perspectiva do cuidado ético, da humanização da prática se dá quando os(as) profissionais fazem uso consciente dos seus conhecimentos, sentimentos e valores, buscando uma ação de qualidade e o reconhecimento do usuário como um sujeito de direito (MARTINELLI, 2007).

\section{EIXO F: ENTRAVES PARA O DESENVOLVIMENTO DO EXERCÍCIO PROFISSIONAL COM CUIDADOS PALIATIVOS}

Quando questionadas sobre os principais entraves encontrados para atuação do(a) assistente social junto aos usuários assistidos com cuidados paliativos, foram ratificadas no primeiro grupo a ausência do trabalho multiprofissional e de conhecimento sobre o tema. 


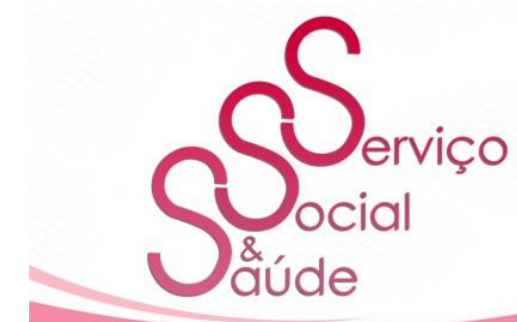

ISSN 2446-5992

(๑) $\odot \odot$

doi: $10.20396 /$ sss.v18i0.8656828

Entraves como eu falei do trabalho multiprofissional a relação multiprofissional, [...] da falta de conhecimento mais aprofundado sobre os cuidados paliativos. (Assistente Social 01).

A maior dificuldade dos cuidados paliativos aqui é a elaboração do protocolo que não tem aqui. (Residente 01).

Sobre a falta ou a fragilidade de um trabalho multiprofissional, Silva e Silveira (2015) indicam esta abordagem como essencial para o tratamento com CPs, pois somente haverá atendimento integral do usuário se houver envolvimento de toda a equipe.

No segundo grupo, prevaleceu a compreensão da ausência de espaço e valorização institucional para o trabalho com cuidados paliativos, seja administrativamente, seja entre os profissionais, conforme destacado nas falas a seguir:

Os entraves são mesmo de ordem administrativa, as condições que a instituição não dá. (Assistente Social 03).

Primeira coisa é [...] capacitação para atuação. [...] no HU que é meu espaço de prática de cotidiano, o que eu percebo é que ainda há muito do interesse individual das pessoas e não institucionalmente um interesse numa política e uma responsabilidade, uma resolutividade, um encaminhamento para a estruturação do serviço. (Assistente Social 04).

Muitos, primeiro o que eu falei sobre consentimento [...] sobre consenso, o que é (sic) cuidados paliativos ainda é, por incrível que pareça, um assunto pouco trabalhado. De forma geral, alguns poucos profissionais têm interesse na temática, buscam conhecer, outros não querem saber, outros pensam que a morte é o fim e que não precisa. [...] não ter medidas de conforto que vão ser suficientes pra (sic) um fim que é iminente, meio que anula o processo de cuidados paliativos. (Residente 03).

Assim, observou-se a comprovação do desconhecimento dos CPs por grande parte dos profissionais que compõem as equipes e trabalham com pacientes em fase terminal ou com doenças sem possibilidade de cura, como já destacado por Hermes e Lamarca (2013).

No caso do Serviço Social, ao permear "[...] a estrutura organizacional como um todo, participando da malha de interações que se processa no contexto hospitalar" (MARTINELLI, 2003 apud ROMÃO, 2012, p. 33), tanto o desenvolvimento, quanto os resultados do seu trabalho são diretamente impactados pelas condições objetivas de que dispõe, embora ambos 


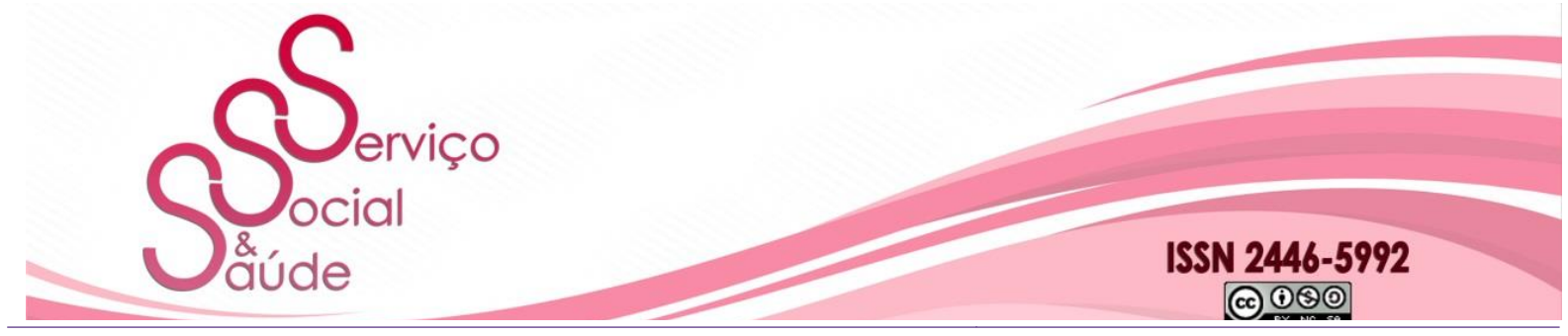

doi: $10.20396 /$ sss.v18i0.8656828

não estejam restritos a elas, pois o domínio das três dimensões que compõem a profissão será determinante para que o(a) profissional contribua junto a usuários e familiares assistidos com CPs na circunscrição das estratégias de intervenção social, detecção das necessidades desses sujeitos e consequente valorização de suas particularidades, auxílio no estabelecimento de objetivos para o cuidado ético e segurança dos envolvidos, mediação entre usuário/família/equipe, e informação, orientação, facilitação dos recursos da rede assistencial para continuidade do cuidado (CÁRCER, 2000 apud ROMÃO, 2012).

Outrossim, embora não se ignore os limites impostos pela realidade, considera-se que o norte para que o trabalho do(a) assistente social com cuidados paliativos seja competente parte do entendimento da necessidade de ir além da execução de tarefas imediatas para uma atuação consciente e ativa no sentido propositivo, o que lhe exige compreensão do que são os CPs, de quais as competências que lhes são atribuídas neste trabalho e dos saberes que deverão ser acionados para sua concretização.

\section{CONSIDERAÇÕES FINAIS}

A partir da pesquisa ora apresentada, percebeu-se que, embora os cuidados paliativos sejam compreendidos como estratégias terapêuticas a serem aplicadas por equipe multiprofissional para proporcionarem maior conforto e alívio do sofrimento de usuários com doenças progressivas e sem perspectiva de melhora e de seus familiares, ainda há um alto índice de desconhecimento a seu respeito entre os profissionais da saúde, o que dificulta sua oferta na rede de assistência à saúde, seu atendimento de forma integral e a qualidade das ações desenvolvidas.

No que concerne às assistentes sociais e Residentes que atuam no HULW, verificou-se uma visão limitada dos CPs à sua vinculação com cuidados destinados a pacientes em estado terminal, aproximação com a temática apenas no cotidiano dos serviços e, por conseguinte, amplo desconhecimento do que são e de quais as suas atribuições e competências nessa estratégia terapêutica, além de baixo desenvolvimento de ações em equipes que atuam com cuidados paliativos, o que em parte foi explicado por deficiências no processo formativo em 


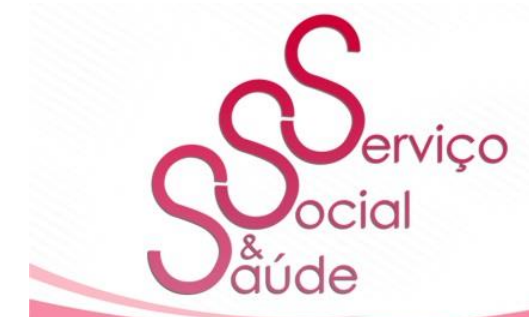

ISSN 2446-5992

(C) (1) (3)

doi: $10.20396 /$ sss.v18i0.8656828

relação à temática e pela inexistência de condições objetivas favoráveis a este tipo trabalho na instituição onde atuam.

Apesar da baixa compreensão e incipiente intervenção com cuidados paliativos, as assistentes sociais e Residentes entrevistadas consideraram haver idealmente congruência entre aqueles e o PEPP. Neste sentido, para além das limitações objetivas, para que esta congruência se concretize e o PEPP se materialize, é mister que o(a) assistente social se aproprie adequadamente da temática e possua domínio das dimensões que compõem a profissão, de modo a empreender um cuidado ético e um trabalho consciente e ativo junto a usuários e familiares assistidos com CPs, voltado à ampliação do modo de olhar e cuidar destes sujeitos.

Entre as estratégias necessárias ao trabalho de assistentes sociais com cuidados paliativos destaca-se o saber ouvir, o acolhimento, o conhecimento dos serviços institucionais e da rede de assistência, a apropriação da realidade, a articulação com a equipe assistencial, a integração com a família, sempre na perspectiva de direito e segurança de usuários e familiares e, ainda que os CPs devam ser compreendidos particularmente em cada caso, é necessário manter a dimensão universalista e democrática que subjaz o PEPP, de modo a evitar incorrer em práticas terapêuticas, simplificadoras ou imediatistas que se afastam do conceito de integralidade a que os cuidados paliativos estão associados.

Enviado em fevereiro 2018 - aprovado em janeiro de 2019

\section{REFERÊNCIAS}

ANCP, Organização de Serviços em Cuidados Paliativos. Recomendações da ANCP. Rio de Janeiro, 2006. Disponível em:

<http://www.apcp.com.pt/uploads/Recomendacoes_Organizacao_de_Servicos.pdf >.Acesso em: 24 abr. 2017. 


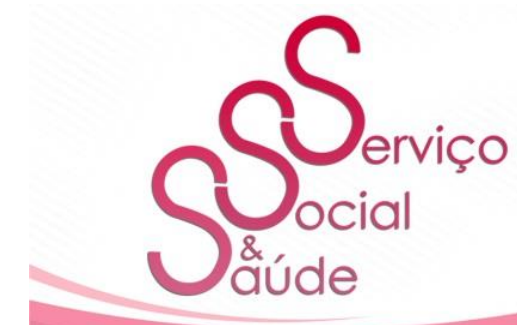

ISSN 2446-5992

(c) (1) (3)

doi: $10.20396 /$ sss.v18i0.8656828

ANDRADE, L. Trajetórias no limiar da vida e da morte: cuidados paliativos na assistência domiciliar. 2007. 199 f. Tese (Doutorado em Serviço Social), Pontifícia Universidade Católica de São Paulo - PUC-SP, São Paulo, 2007.

ANDRADE, L. Serviço Social. In: OLIVEIRA, R. A. de. Cuidado Paliativo. São Paulo: Conselho Regional de Medicina do Estado de São Paulo, 2008. p. 69-73.

ANDRADE, Letícia. O papel do assistente social na equipe. In: CARVALHO, R. T. de; PARSONS, H. A. (Orgs.). Manual de Cuidados Paliativos ANCP. ampl. e atual. 2. ed. São Paulo: ANCP, 2012a, p. 341-344.

ANDRADE, Letícia. Providências práticas para toda a família. In: CARVALHO, R. T. de; PARSONS, H. A. (Orgs.). Manual de Cuidados Paliativos ANCP. ampl. e atual. 2. ed. São Paulo: ANCP, 2012b, p. 400-407.

BARROS, N. C. B, et al. Cuidados Paliativos na UTI: compreensão, limites e possibilidades por enfermeiros. Revista de Enfermagem da UFSM, v. 2, n. 3, p. 630-640, set./dez. 2012. BRAVO, M. I. S; MATOS, M. C de. Projeto Ético-Político do Serviço Social e sua Relação com a Reforma Sanitária: elementos para o debate. In: MOTA, A. E. [et al.]. (Orgs.) Serviço Social e Saúde: Formação e Trabalho Profissional, São Paulo: OPAS; OMS, Ministério da Saúde, 2006. p. 197-217.

CARDOSO, D. H. et al. Cuidados Paliativos na assistência hospitalar: a vivência de uma equipe multiprofissional. Texto \& Contexto Enfermagem, Florianópolis, v. 22, n. 4, p. 1134-1141, out./dez. 2013.

CARVAlHO, R. T. de; ARANTES, A. C. de L, Q. UTI. In: OlIVEIRA, R. A. de. Cuidado Paliativo. São Paulo: Conselho Regional de Medicina do Estado de São Paulo, 2008. p. 178194.

CONSELHO FEDERAL DE SERVIÇO SOCIAL. Código de Ética do/a Assistente Social. 10. ed. rev. e atual., Brasília: CFESS, 2012.

CONSELHO FEDERAL DE SERVIÇO SOCIAL. Parâmetros para Atuação de Assistentes Sociais na Política de Saúde. Brasília: CFESS, 2010. (Série: Trabalho e Projeto Profissional nas Políticas Sociais). 


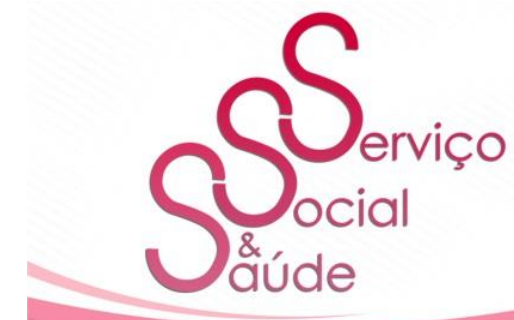

ISSN 2446-5992

(๑) 100

doi: $10.20396 /$ sss.v18i0.8656828

EAPC. Palliative Care - A Human Right. 2013. Disponível em:

<http://www.eapcnet.eu/LinkClick.aspx?fileticket=6AmBAJNDb8A\%3d\&tabid=1871>.

Acesso em 21 mai. 2017.

FONSECA, A. C.; FONSECA, M. de J. M. da. Cuidados Paliativos para idosos na unidade de terapia intensiva: realidade factível. Sicentia Medica, Porto Alegre, v. 20, n. 4, p. 301-309, 2010.

FRACOLLI, L. A. et al. Conceito e prática da integralidade na Atenção Básica: a percepção das enfermeiras. Revista Escola de Enfermagem, São Paulo, , v. 45, n. 5, p. 1135-1141, 2011.

HERMES, H. R.; LAMARCA, I. C. A. Cuidados paliativos: uma abordagem a partir das categorias profissionais. Ciência \& Saúde Coletiva, Rio de Janeiro, v. 18, n. 9, p. 2577-2588, 2013.

MACIEL, M. G. S. Definições e Princípios. In: OLIVEIRA, R. A. de. Cuidado Paliativo. São Paulo: Conselho Regional de Medicina do Estado de São Paulo, 2008. p. 15-32.

MARTINELLI, M. L. O exercício profissional do assistente social na área da saúde: algumas reflexões éticas. Serviço Social \& Saúde, Campinas, v. 6, n. 6, p. 21-33, maio 2007.

MATOS, I. B.; TOASSI, R. F. C.; OLIVEIRA, M. C. de. Profissões e ocupações de saúde e o processo de feminização: tendências e implicações. Athenea Digital, Barcelona, v. 13, n. 2, p. 239-244, 2013.

MATUSMOTO, D. Y. Cuidados Paliativos: conceito, fundamentos e princípios. In: CARvalho, R. T. de; PARSONS, H. A. (Orgs.). Manual de Cuidados Paliativos ANCP. ampl. e atual. 2. ed. São Paulo: ANCP, 2012, p. 23-30.

MENDES, E. C.; VASCONCELLOS, L. C. F. de. Cuidados paliativos no câncer e os princípios doutrinários do SUS. Saúde Debate, Rio de Janeiro, v. 39, n. 106, p. 881-892, jul./set. 2015.

MIOTO, R. C. T.; NOGUEIRA, V. M. R. Serviço Social e Saúde - desafios intelectuais e operativos. SER Social, Brasília, v. 11, n. 25, p. 221-243, jul./dez. 2009.

MORITZ, R. D. et al. Terminalidade e cuidados paliativos na unidade de terapia intensiva.

Revista Brasileira de Terapia Intensiva, São Paulo, v. 20, n. 4, p. 422-428, 2008. 


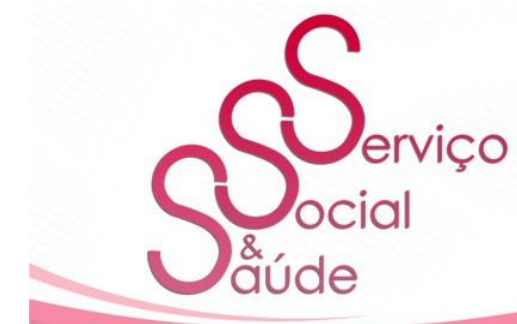

ISSN 2446-5992

(๑) 100

doi: $10.20396 /$ sss.v18i0.8656828

NICKEL, L. et al. Grupos de pesquisa em cuidados paliativos: a realidade brasileira de 1994 a 2014. Escola Anna Nery, v. 20, n. 1, p. 70-76, 2016.

NOGUEIRA, V. M. R; MIOTO, R. C. T. Desafios atuais do Sistema Único de Saúde - SUS e as exigências para os Assistentes Sociais. In: MOTA, A. E. [et al.]. (Orgs.) Serviço Social e Saúde: Formação e Trabalho Profissional, São Paulo: OPAS; OMS, Ministério da Saúde, 2006. p. 218-241.

OLIVEIRA, A. C. de; SILVA, M. J. P. da. Autonomia em cuidados paliativos: conceitos e percepções de uma equipe de saúde. Acta Paulista de Enfermagem, São Paulo, v. 23, n. 2, p. 212-217, 2010.

RABELlO, C. A. F. G.; RODRIGUES, P. H. de A. Saúde da família e cuidados paliativos infantis: ouvindo os familiares de crianças dependentes de tecnologia. Ciência \& Saúde Coletiva, Rio de Janeiro, v. 15, n. 2, p. 379-388, 2010.

ROMÃO, C. M. J. Cuidados Paliativos - uma reflexão sobre as competências profissionais do assistente social. 2012. 158 f. Dissertação (Mestrado em Formação de Adultos e Desenvolvimento Local), Instituto Politécnico de Portalegre - Escola Superior de Educação, Portalegre, 2012.

SBGG. Vamos falar de cuidados paliativos. 2015. Disponível em: <http://sbgg.org.br/wpcontent/uploads/2015/05/vamos-falar-de-cuidados-paliativos-vers--o-online.pdf >. Acesso em: 24 abr. 2017.

SILVA, D. I. S. da; SILVEIRA, D. T. Cuidados Paliativos : desafio para a gestão e políticas em saúde. Revista Eletrônica Gestão \& Saúde. Vol.06, №. 01, Ano 2015 p.501-13

SILVA, R. V. G. O. da; RAMOS, F. R. S. Integralidade em Saúde: revisão de literatura.

Ciência, Cuidado e Saúde, Maringá, v. 9, n. 3, p. 593-601, jul./set. 2010.

SILVA, E. P. da; SUDIGURSKY, D. Concepções sobre cuidados paliativos: revisão bibliográfica. Acta Paulista de Enfermagem, São Paulo, v. 21, n. 3, p. 504-508, 2008.

SIMÃO, A. B. et al. A atuação do Serviço Social junto a pacientes terminais: breves considerações. Serviço Social \& Sociedade, São Paulo, n. 102, p. 352-364, abr./jun. 2010. 


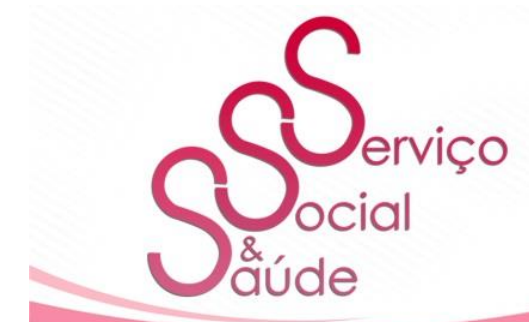

\section{ISSN 2446-5992}

(1) (10)

doi: $10.20396 /$ sss.v18i0.8656828

28

TAQUEMORI, L. Y.; SERA, C. T. N. Interface intrínseca: equipe multiprofissional. In: OliVEIRA, R. A. de. Cuidado Paliativo. São Paulo: Conselho Regional de Medicina do Estado de São Paulo, 2008. p. 55-57.

OliveIRA, R. A. de. Cuidado Paliativo. São Paulo: Conselho Regional de Medicina do Estado de São Paulo, 2008.

TIBURTINO, L. C. Relações de Gênero e Processos de Trabalho no Serviço Social Temporalis, Brasília, ano 15, n. 29, p. 247-264, jan./jun. 2015.

UGARTE, O. Contexto Normativo dos Cuidados Paliativos no SUS. 2014. 45f.

Monografia (Especialização em Saúde Coletiva e Educação na Saúde), Faculdade de Educação - Universidade Federal do Rio Grande do Sul, Porto Alegre, 2014.

ZACARIAS, C. C. et al. Implantação de tecnologias de cuidado em unidade de terapia intensiva aos usuários e seus familiares. Ciência, Cuidado e Saúde, Maringá, v. 8, n. 2, p. 161-168, abr./jun. 2009. 